\title{
Sermão de Santo Antônio aos Peixes: uma análise das estratégias de manipulação e dos investimentos temáticos e figurativos
}

DOI: http://dx.doi.org/10.21165/el.v49i3.2504

\section{Cássia Lacerda Soares ${ }^{1}$}

\section{Resumo}

Ao observar a ação - relação de produção e/ou de transformação entre o sujeito e o objeto -, a Semiótica discursiva reúne condições para analisar a manipulação - espaço da relação intersubjetiva, no qual um sujeito age sobre outro para levá-lo a querer e/ ou dever fazer alguma coisa. Considerando esse olhar propiciado pela teoria, busca-se, neste artigo, verificar as estratégias de manipulação adotadas pelo narrador face ao narratário, sujeitos inscritos no texto, articulando-as à mobilização de investimentos temáticos e figurativos no nível discursivo, a partir da leitura do "Sermão de Santo Antônio aos Peixes", do Padre Antônio Vieira. Nessa conjuntura, procura-se apresentar um olhar semiótico acerca das ideias desse missionário, as quais compõem uma mensagem sempre atual sobre questões transversais que se configuram como pertinentes para qualquer sociedade.

Palavras-chave: manipulação; tema; figuras; semiótica; sermão.

1 Universidade Federal de Mato Grosso do Sul (UFMS), Campo Grande, Mato Grosso do Sul, Brasil; cassiasoares1327@gmail.com; https://orcid.org/0000-0001-8590-0929 


\section{"Sermón de San Antonio a los Peces": un análisis de las estrategias de manipulación y de las inversiones temáticas y figurativas}

\section{Resumen}

Al observar la acción - relación de producción y/o transformación entre el sujeto y el objeto - la Semiótica discursiva reúne condiciones para analizar la manipulación - espacio de la relación intersubjetiva, en el que un sujeto actúa sobre otro para llevarlo a querer y/o deber hacer algo. Teniendo en cuenta esa perspectiva, este artículo busca verificar las estrategias de manipulación adoptadas por el narrador en relación al narratario, sujetos inscritos en el texto, articulándolas con la movilización de inversiones temáticas y figurativas a nivel discursivo, desde la lectura del "Sermón de San Antonio a los Peces, por el Padre Antonio Vieira. En esa coyuntura, se busca presentar una mirada semiótica acerca de las ideas de ese misionero, las cuales componen un mensaje siempre actual sobre cuestiones transversales que se configuran como pertinentes para cualquier sociedad.

Palabras clave: manipulación; tema; figuras; semiótica; sermón.

\section{Palavras iniciais}

Vista como uma teoria da significação que busca explicar as condições de apreensão e de produção de sentido, a chamada Semiótica francesa, discursiva ou Semiótica greimasiana foi desenvolvida por Algirdas Julien Greimas, linguista lituano radicado na França.

Ao se interessar pelos caminhos que conduzem à significação, essa teoria possui como objeto de estudo o processo discursivo-textual que produz o sentido, domínio infinitamente vasto, do qual se ocupam outras disciplinas que constituem a área das ciências humanas, como a filosofia, a antropologia e a sociologia, entre outras. Porém, uma restrição impõese segundo Bertrand (2003b): a semiótica se interessa pelo "parecer do sentido", que se apreende por meio das formas de linguagem e, mais concretamente, dos discursos que 0 manifestam. Trata-se, pois, de uma "abordagem relativista de um sentido, se não sempre incompleto, pelo menos sempre pendente nas tramas do discurso" (BERTRAND, 2003b, p. 21).

Situando-se na tradição saussuriana e hjelmsleviana, segundo a qual a significação é a criação ou a apreensão de diferenças, a semiótica de Greimas procura determinar o sistema estruturado de relações que produzem o sentido do texto. Assim, o texto passa a ser visto como um objeto de significação, e a partir dele se estudarão os mecanismos que o engendram e o constituem como um todo significativo. 
Em outras palavras, a Semiótica procura descrever e explicar o que o texto diz e como ele faz para dizer o que diz, examinando, em primeiro lugar, o seu plano de conteúdo, concebido sob a forma de um percurso gerativo de sentido que comporta três níveis - o fundamental, o narrativo e o discursivo -, que vão das estruturas mais simples e abstratas até as mais complexas e concretas. Cabe ressaltar que a noção de tal percurso derivou do trabalho de Vladimir Propp sobre a narrativa; este buscou as invariantes narrativas, os elementos que fazem com que uma narrativa seja configurada como tal. Sendo uma teoria sobre o sentido, por meio do olhar semiótico, a narrativa aparecerá, antes de qualquer coisa, como uma transformação de conteúdo, conforme assevera Bertrand (2003a).

A partir das noções do simulacro teórico-metodológico greimasiano, este trabalho efetua um recorte e busca realizar algumas incursões, em especial, na sintaxe das estruturas narrativas, para verificar as estratégias de manipulação adotadas pelo narrador face ao narratário, e na semântica das estruturas discursivas, para investigar a reiteração dos temas e a recorrência das figuras que revestem o conjunto de isotopias presentes no texto.

Nessa perspectiva, dos inúmeros textos de Padre Antônio Vieira, elege-se, para este estudo, o Sermão de Santo Antônio aos Peixes, o qual se insere em uma perspectiva de denúncia do imaginário colonial português. Pregado em São Luís do Maranhão, em 13 de junho de 1654, constitui um importante documento acusatório das injustiças e contradições da sociedade do período, especificamente a da região do Maranhão e GrãoPará, marcada pelo domínio dos colonos que, ávidos de poder, escravizavam os indígenas.

Tal sermão expressa, sobretudo, a indignação diante do contexto em que os preceitos cristãos são ocultados pelos interesses pessoais e corporativistas. Enquanto os missionários defendiam a libertação dos índios, os colonos lutavam pela continuidade da exploração de mão de obra desses povos, ignorando as leis da época.

Nessa atmosfera, irrompe o Sermão de Santo Antônio aos Peixes, que é proferido dias antes de o padre jesuíta embarcar novamente para Portugal, a fim de denunciar, junto à Corte, as arbitrariedades contra os indígenas, que constatara em seu retorno ao Brasil. O sermão vale-se da figura do santo católico Santo Antônio de Lisboa ou de Pádua, cuja ação de pregar aos peixes, ainda como Frei Antônio, é imitada por Vieira.

Assim como Santo Antônio, que em 1223, em Rimini, dirige seu sermão aos peixes na costa do mar Adriático, em protesto contra os hereges da região, os quais impediam o povo de ouvir as suas pregações, Vieira também invoca os peixes tecendo considerações sobre as virtudes e os vícios humanos. Ao fazê-lo, refere-se a alguns peixes da região do Maranhão estabelecendo, assim, uma relação metafórica com os colonizadores, a fim de provocar um efeito de sentido mais contundente entre os ouvintes. 
A partir disso, como suporte teórico elegem-se os estudos acerca da Semiótica discursiva de Barros (2001, 2005a, 2005b), Bertrand (2003a, 2003b), Fiorin (1999, 2005), Greimas e Courtés (1979), Cardoso (2015) e Batistote (2012). Para os apontamentos acerca dos escritos de Vieira, recorre-se aos trabalhos de Mügge e Conte (2017).

\section{Um pouco de teoria}

\section{0 projeto semiótico de Greimas}

Ao longo do percurso da história da linguagem, as preocupações com os estudos da língua se modificam e, a partir das teorias da significação, busca-se incluir o elemento excluído por Ferdinand de Saussure, o sujeito, e passa-se a dar ênfase à relação entre a linguagem e o mundo, entre o falante e seu ouvinte, bem como entre o locutor e a língua.

Nessa visada, irrompem as raízes dos fundamentos da teoria semiótica desenvolvida por Greimas que, ao refletir sobre as condições pelas quais é viável um estudo científico da significação, funda um projeto de ciência, cuja indicação central incide sobre o sentido construído no âmbito do texto.

O linguista lituano constrói uma semântica linguística que se volta à análise da significação assim como é fornecida pelo código da língua. O estudo dessa semântica, por sua vez, deve atender a três condições: ser sintagmático, pois seu escopo é estudar a produção e a interpretação dos textos; ser gerativo, visto que a proposta greimasiana concebe o texto como um percurso gerativo, que vai do nível mais simples e abstrato ao mais complexo; e ser geral, visto que, no estudo da significação, a unicidade do sentido pode manifestar-se sob diversas configurações de texto, verbais, visuais ou sincréticos, por exemplo.

Ultrapassando os limites da frase e concebendo o texto como unidade de sentido, a semiótica greimasiana considera que o sentido da frase depende do sentido do texto. A partir disso, tal teoria pretende, de maneira imanente, apreender o sentido no interior do próprio texto; procura, então, descrever e explicar o que o texto diz e como ele faz para dizer o que diz.

Nessa perspectiva, a proposta de Greimas situa sua intervenção no âmbito de uma teoria da linguagem e de sua realização em discurso e postula, sobretudo, que o texto forma um "todo de significação que comporta em si mesmo os princípios de sua própria completude: um mundo de representações vai se introduzindo ao longo das frases, abrindo-se desde a primeira e fechando-se após a última" (BERTRAND, 2003a, p. 13).

O projeto semiótico greimasiano conseguiu desenvolver uma análise interna e consistente e inaugurou novas perspectivas para a observação externa dos significados no texto, 
conseguindo realizar um estudo que aliasse o interno, a discursivização, e o externo, a relação enunciado/enunciação. Por meio disso, o texto passou a ser explicado a partir de um modelo que o trata como sendo o produto de um percurso gerativo com três patamares que se complementam, mas que podem ser estudados separadamente.

A noção de tal percurso parte do nível mais simples e abstrato para o mais complexo e concreto. Segundo Fiorin (1999, p. 3), "constitui ele um simulacro metodológico, para explicar o processo de entendimento, em que o leitor precisa fazer abstrações, a partir da superfície do texto, para poder entendê-lo". Diante disso, o percurso gerativo de sentido deve ser entendido como um modelo hierárquico, em que se correlacionam as estruturas fundamentais, as estruturas narrativas e as estruturas discursivas.

Para cada um dos níveis do percurso se estabelece uma sintaxe e uma semântica. Cabe ressaltar que, neste trabalho, serão realizadas incursões analíticas, em especial, com algumas noções mobilizadas no nível narrativo e no discursivo. No entanto, fazse necessário apresentar, de modo sucinto, o nível fundamental, primeiro patamar desse percurso, o qual busca analisar em sua semântica as categorias mais gerais que organizam o sentido do texto e o encadeamento de seus componentes em sua dimensão sintática.

No simulacro teórico-metodológico proposto por Greimas, no segundo patamar, encontra-se o nível narrativo. Nele, o percurso fundamental se manifesta sob a forma de transformações operadas por sujeitos que assumem papéis actanciais (actantes). A partir das estruturas narrativas, cada texto é composto por um ou mais programas que compreendem uma mudança de estado(s), ou seja, uma transformação na relação entre sujeito e objeto ou entre o sujeito e um outro sujeito.

Os textos não são vistos como narrativas mínimas, mas, ao contrário, são narrativas complexas, em que uma série de enunciados de fazer e de ser organiza-se hierarquicamente. Desse modo, evidencia-se a relação de transitividade entre o homem e as coisas e a relação entre os homens, o que dá origem aos papéis de destinador e destinatário.

Para formar o esquema narrativo, as narrativas organizam-se em enunciados de estado (marcados pela relação de junção conjunta ou disjunta entre um sujeito e um objeto) ou de fazer (responsáveis pela passagem de um enunciado de estado a outro), em programas de doação de competência semântica ou modal, de performance, de interpretação ou retribuição e em percurso do destinador-manipulador, do sujeito e do destinador-julgador. Uma narrativa complexa estrutura-se numa sequência canônica que compreende quatro fases: a manipulação, a competência, a performance e a sanção. Dada a importância da etapa de manipulação para este artigo, ela será tratada de modo à parte no próximo tópico. 


\section{A manipulação}

A manipulação deve ser entendida como um contrato fiduciário, em que o destinador, graças a um fazer persuasivo, busca fazer com que o destinatário, ao desempenhar o fazer interpretativo que lhe cabe, creia ser verdadeiro o discurso do outro e o próprio destinador. Há, dessa forma, o estabelecimento de uma estreita vinculação entre a confiança e a crença, o que permite falar em contrato.

Segundo Barros (2001), a confiança entre os homens fundamenta a confiança nas palavras deles sobre as coisas e o mundo e, finalmente, a confiança ou a crença nas coisas e no mundo. A mesma autora explica que o "fazer-persuasivo ou fazer-crer do destinador tem como contrapartida o fazer-interpretativo ou o crer do destinatário, de que decorre a aceitação ou a recusa do contrato" (BARROS, 2005b, p. 31). Assim, conforme Barros (2001), o percurso do destinador-manipulador pode ser resumido em três etapas: o contrato fiduciário, em que é convencionado um mínimo de confiança; o espaço cognitivo da persuasão e da interpretação; e a aceitação ou recusa do contrato.

Para atingir o destinatário, o sujeito operador, pode se valer de quatro estratégias de manipulação: a sedução (juízo positivo), a provocação (juízo negativo), a intimidação (oferta de valores disfóricos) e a tentação (oferta de valores eufóricos). Essas figuras são classificadas em dois critérios: o da competência do manipulador para o fazer persuasivo e o da alteração modal desempenhada na competência do sujeito manipulado. De acordo com Barros (2001), no primeiro caso, o destinador persuade pelo saber, seduzindo e provocando, ou pelo poder, intimidando e tentando. Já o segundo critério aplica-se à transformação da competência modal do sujeito manipulado, que passa a querer ou a dever-fazer. O querer-fazer resulta da sedução e/ou da tentação, o dever-fazer, da provocação e/ou da intimidação.

Para tentar e intimidar, o destinador oferecerá valores que ele acredita desejados ou temidos pelo destinatário. Por outro lado, ao seduzir e provocar, o manipulador expõe imagens positivas ou negativas do manipulado e de sua competência. Nesses casos, explica Barros (2005a), que o manipulado, para preservar ou para evitar sua imagem feita pelo destinador-manipulador, busca realizar o que lhe é proposto.

Em qualquer um dos tipos de manipulação, o destinatário assume a posição de obediência ou de privação de liberdade, uma vez que possui algumas escolhas: realizar o que o destinador propõe e receber valores e imagens desejados, ou evitar valores e imagens temidos, ou ainda não fazer e não obter os valores e os juízos de desejo, ou sofrer as consequências dos valores e imagens temidos.

A ordem das estratégias de manipulação dependerá da relação entre manipulador e manipulado, e ela só será bem-sucedida quando o sistema de valores em que ela está 
assentada for compartilhado pelo manipulador e pelo manipulado, quando houver certa cumplicidade entre eles. No simulacro da ação, o destinador é dotado de um saber e um poder-fazer, ou seja, possui competência para a realização de sua performance. Voltemos nossa atenção, agora, para os mecanismos da semântica discursiva.

\section{0 discurso: temas e figuras}

Avançando pelos elementos constituintes do percurso gerativo do sentido, chega-se ao patamar mais superficial do percurso, o mais próximo da manifestação textual, o nível discursivo. Barros (2005b, p. 53) explica que, "pela própria definição do percurso gerativo, as estruturas discursivas são mais específicas, mas também mais complexas e 'enriquecidas' semanticamente do que as estruturas narrativas e as fundamentais". Em função disso, a especificidade e a complexidade das organizações discursivas são explicadas pelo exame da sintaxe e da semântica do discurso.

As estruturas narrativas convertem-se, nesse nível, em estruturas discursivas quando assumidas pelo sujeito da enunciação que faz uma série de escolhas (de pessoa, de tempo, de espaço, de temas e de figuras), transformando a narrativa em discurso. A enunciação caracteriza-se, em primeira definição, como a instância de mediação entre estruturas narrativas e discursivas.

Atribuiu-se especial importância às estruturas discursivas por serem consideradas o lugar de desvelamento da enunciação e de manifestação dos valores sobre os quais está assentado o texto. Em nosso recorte, focalizaremos, em especial, os percursos temáticos e os investimentos figurativos que se originam a partir dos valores de uma narrativa.

Segundo Barros (2005b, p. 69), tematizar um discurso consiste em "formular os valores de modo abstrato e organizá-los em percursos"; já para analisar os percursos, "devemse empregar princípios da análise semântica de determinar os traços ou semas que se repetem no discurso e o tornam coerente". Quanto ao procedimento de figurativização, ainda de acordo com a autora, "figuras do conteúdo recobrem os percursos temáticos abstratos e atribuem-lhes traços de revestimento sensorial" (BARROS, 2005b, p. 72).

Por meio dos investimentos temáticos e figurativos, são estabelecidas diferentes maneiras de ver, sentir e representar o mundo por meio de discursos. Deve-se ter em mente a distinção entre ambos: entendidos como um investimento semântico, os temas não remetem ao mundo natural. Nas palavras de Fiorin (2011, p. 91), "são categorias que organizam, categorizam, ordenam os elementos do mundo natural: elegância, vergonha, raciocinar, calculista, orgulhoso" e vinculam-se ao pensamento abstrato; por outro lado, as figuras aludem a algo existente no mundo natural, por exemplo, "árvore, vaga-lume, sol, correr, brincar, vermelho, quente" (FIORIN, 2011, p. 91), relacionando-se ao pensamento concreto. 
O estudioso salienta, no entanto, que "é preciso ter em mente que concreto e abstrato não são termos polares que se opõem de maneira absoluta, mas constituem um continuum em que se vai, de maneira gradual, do mais abstrato ao mais concreto" (FIORIN, 2011, p. 91). Nesse sentido, tema e figura não são termos que se opõem, mas que se complementam, uma vez que estão direta ou indiretamente interligados na constituição e na concretização dos sentidos, pois enquanto a tematização tem como função explicar os fatos e as coisas do mundo, conduzindo à interpretação da realidade, a figurativização, por sua vez, mediante elementos concretos, possui como finalidade principal criar um simulacro do mundo real, ou seja, projetar um efeito de realidade.

A figuratividade faz surgir aos olhos do leitor a aparência do mundo sensível e o conduz à dimensão das figuras do discurso, estabelecendo uma relação imediata e uma correspondência entre as figuras semânticas, a percepção e as formas da sensorialidade, conforme assevera Bertrand (2003b). A figuratividade permite, dessa forma, localizar no discurso um efeito de sentido particular, o qual consiste em tornar sensível a realidade.

Para o mesmo autor, a dimensão figurativa da significação, superficial e rica, de imediato acesso ao sentido, é tecida por isotopias semânticas, e reveste outras dimensões, mais abstratas e profundas de um texto ou de um discurso: "uma imagem do mundo se delineia, instalando tempo, espaço, objetos e valores" (BERTRAND, 2003b, p. 154). Para ser compreendido, o figurativo precisa ser assumido por um tema que dá valor e sentido às figuras. Batistote (2012, p. 45) explica que "a tematização é a repetição de determinados traços semânticos que remetem a valores abstratos e que, pela recorrência no discurso, constroem a coerência dele, ou seja, as possibilidades de leitura que ele oferece".

Os temas espalham-se pelo texto e são recobertos pelas figuras. A reiteração dos temas e a recorrência das figuras no discurso instauram a isotopia. Barros (2005b) distingue dois tipos de isotopia: a temática e a figurativa. A primeira surge da repetição de unidades semânticas abstratas, em um mesmo percurso temático; já a segunda define-se pela redundância de traços figurativos, pela associação de figuras similares. A recorrência de figuras atribui ao discurso uma imagem organizada e completa da realidade. Com a análise dos percursos ou linhas isotópicas, descobrem-se possibilidades de leituras que asseguram a coerência semântica do discurso, uma das condições para que o texto seja coerente.

\section{Análise}

Antes de adentrar no percurso analítico a ser desenvolvido acerca do sermão de Antônio Vieira, cabe pontuar que, ao recorrer à definição de Greimas e Courtés (1979), empregase o termo narrador para nomear o enunciador instalado no texto, como aquele que narra, e narratário para seus enunciatários, aqueles para quem se narra. Considera-se de fundamental importância, ainda, enfatizar que narrador e narratário se estabelecem na criação do texto, ambos são funções do texto, segundo Cardoso (2015). 
O simulacro discursivo do enunciador, o narrador, explicitamente instalado no discurso possui o saber, o poder e o querer narrar; em função disso, busca ganhar a confiança do narratário, levando-o a crer que o que se narra é verdade. Estabelece-se, de acordo com Fiorin (2016), uma "convenção fiduciária" entre o enunciador e o enunciatário determinante do estado veridictório do que está sendo narrado, conforme se verifica no decorrer da análise aqui proposta.

Visto como um dos textos mais pessimistas de Antônio Vieira, segundo Mügge e Conte (2017), o Sermão de Santo Antônio aos Peixes constitui um registro da surpreendente imaginação, habilidade oratória e poder satírico do missionário que, ao valer-se de uma construção literária e argumentativa, objetiva com sua narrativa louvar algumas virtudes humanas e, principalmente, censurar com severidade alguns vícios dos colonos portugueses.

Pregado três dias antes de Vieira embarcar ocultamente para Portugal, onde pretendia obter uma legislação mais justa para os índios, prejudicando, assim, os interesses dos colonos europeus, o sermão é dividido em seis partes e, em cada uma delas, o padrenarrador se apresenta como um sujeito que adquire um saber-fazer, que torna possível o fazer, ou seja, possui competências para realizar a performance de persuadir e manipular os seus narratários.

Nesse contexto, referindo-se à passagem em que Jesus, ao falar com seus pregadores, os designa de "sal da terra", esperando que eles alcancem, com a prática missionária, o mesmo efeito do sal: o de preservar, o narrador, na primeira parte do sermão, a partir desse episódio bíblico, começa a levantar algumas razões que possam justificar o porquê de a terra estar tão corrupta. Ao tomar como base a realidade maranhense, questiona que "o efeito do sal é impedir a corrupção, mas quando a terra se vê tão corrupta como está a nossa, havendo tantos nela que têm ofício de sal, qual será, ou qual pode ser a causa desta corrupção?" (VIEIRA, 2016 p. 12). Como explicação, aponta duas possibilidades: "Ou é porque o sal não salga, ou porque a terra se não deixa salgar" (VIEIRA, 2016, p. 1). O sal, assim, segundo o sermão, deveria conservar o são e preservá-lo para que não se corrompesse, pois essas duas propriedades tinham as pregações de Santo Antônio e deveriam ter as de todos os pregadores.

A partir disso, o enunciador instalado no texto como narrador, coloca em evidência o cenário de exploração de mão de obra indígena em que estava inserido o Maranhão e sugere que a ineficiência dessa sociedade estaria nos atos dos pregadores e na insensibilidade das pessoas, de modo que nem mesmo Jesus seria capaz de eliminá-la.

2 Neste artigo, utilizamos uma versão on-line de 2016 do Sermão de Santo Antônio aos Peixes, de Antônio Vieira, texto publicado originalmente em 1654. 
Inserido nesse ambiente fragilizado, o missionário-narrador busca mostrar a efemeridade da alma humana que se deixa influenciar pelo encantamento do poder e dos vícios, por meio da reprodução da atitude de Santo Antônio, que, em vez de pregar aos homens, pregou aos peixes, uma vez que esses seres não sustentam a doutrina da heresia.

Ao pensar na manipulação, observa-se que, nessa parte do sermão, o narrador é um destinador-manipulador que possui o dever- fazer diante do contexto apresentado. Assim, tenta persuadir seu narratário por meio da provocação, ou seja, expõe um juízo negativo acerca dos pregadores e das pessoas daquela sociedade desigual e vulnerável. A atribuição de competência modal do narrador, para levá-lo a fazer, constitui a manipulação propriamente dita e pressupõe um contrato fiduciário, o qual propõe aos destinatários escutar suas palavras e, por meio delas, enxergar as mazelas daquele lugar e buscar a mudança de comportamentos, de atitudes para acabar com as injustiças presentes no cenário maranhense.

Por outro lado, quanto aos temas e figuras, salta aos olhos a temática da corrupção figurativizada pelas imagens dos pregadores e dos colonos. O sal e a terra se configuram como investimentos figurativos nessa perspectiva, uma vez que, para o pregador instalado no texto, algumas razões podem justificar o motivo de a terra estar tão corrompida: ou a culpa está no sal, equiparado pelo narrador aos anunciadores das palavras de Jesus, ou na terra, que é usada como imagem dos ouvintes. Se a culpa está no sal, é porque os pregadores não pregam a verdadeira doutrina, ou porque dizem uma coisa e fazem outra, ou porque se pregam a si e não a Cristo. Se a culpa está na terra, é porque os ouvintes não querem receber a doutrina, ou imitam as ações dos pregadores e não o que eles dizem, ou ainda porque servem aos seus apetites e não aos de Cristo.

Ao deter-se sobre um dever-fazer, o narrador busca, na segunda parte do sermão, provocar seus narratários, por meio da exaltação da imagem positiva dos peixes, a qual é colocada em contraste com o juízo negativo dos homens. Nesse momento, a figura dos peixes reveste alguns investimentos temáticos que revelam as virtudes entre os homens, recobertos de temas disfóricos, e os seres aquáticos, revestidos de temas eufóricos.

Para o narrador do sermão, os peixes não possuem vaidade, diferentemente dos homens que se deixam levar pela adulação; a temática da obediência também está presente na imagem dos peixes que, conforme o pregador, se tornou evidente quando os peixes ouviram a palavra de Deus pronunciada por Santo Antônio, ao contrário dos homens, que o perseguiram porque ele repreendera seus vícios. Os peixes são revestidos de devoção e quietude; nos homens, por sua vez, estão a fúria e a obstinação.

Para reforçar a contraposição entre animais e humanos, o pregador recupera a afırmação de Aristóteles de que só os peixes não se deixam domar nem domesticar, e declara que, ao contrário do que muitos pensam, não condena essa atitude e recomenda: "Peixes! 
Quanto mais longe dos homens tanto melhor: trato e familiaridade com eles, Deus vos livre" (VIEIRA, 2016, p. 5). Mediante a isso, vale-se da estratégia da provocação, na tentativa de atingir seu destinatário e forçá-lo a agir para alterar o juízo negativo.

A terceira parte do sermão se inicia com uma invocação aos peixes: "Este é, peixes, em comum o natural que em todos vós louvo, e a felicidade de que vos dou o parabém, não sem inveja" (VIEIRA, 2016, p. 6). Mais uma vez, o missionário-narrador recorre à provocação a fim de operar sobre a competência de seus destinatários. Observa-se que o fazer persuasivo do narrador no texto define-se como um fazer-crer e como um fazersaber.

Na sequência do sermão, deparamo-nos com a avaliação particular das virtudes de vários peixes. Assim, o pregador instalado na narrativa faz vários investimentos temáticos a partir da figura de diversas espécies desses animais. O primeiro exemplo é o do peixe de Tobias, que apareceu diante do jovem, de boca aberta, quando ele lavava seus pés à margem do rio. 0 moço, aconselhado pelo anjo Rafael, puxou o animal para a terra e extraiu-lhe o fel, o coração e o fígado, remédios para doenças físicas e psíquicas. O fel serviu para curar a cegueira do pai de Tobias e o coração para espantar o demônio de sua própria casa. Com a figura de tal peixe, o narrador coloca em evidência a temática da cegueira dos homens, dos colonos portugueses.

A estratégia manipuladora do narrador, ao mesmo tempo em que reforça o desprezo ao público, materializa sua presença, estimula sua atenção e provoca uma reação. 0 enunciador do texto se dirige aos presentes e os provoca: "Ah moradores do Maranhão, quanto eu vos pudera agora dizer neste caso! Abri, abri estas entranhas: vede, vede este coração" (VIEIRA, 2016, p. 7). No entanto, corrige-se, em seguida, afirmando: "Mas ah sim, que me não lembrava! Eu não vos prego a vós, prego aos peixes" (VIEIRA, 2016, p. 7).

O tema da força das palavras dos pregadores é figurativizado pela rêmora, um peixe de pequeno porte que se deixa transportar por peixes maiores, tartarugas e barcos. 0 animal, agarrado ao leme da nau, é "freio da nau e leme do leme" (VIEIRA, 2016, p. 7), pois prende e agarra mais do que as âncoras e consegue determinar seu rumo. Assim deveriam ser as palavras dos pregadores; deveriam domar as paixões humanas, como as que habitam os vícios da soberba, da vingança, da cobiça e da sensualidade.

A figura do torpedo reveste o tema da conversão das pessoas. Esse peixe, quando preso ao anzol, faz o braço do pescador tremer, por causa da eletricidade que é capaz de produzir. Esse efeito deveria ocorrer com as palavras dos pregadores, as quais deveriam fazer tremer os corações de seus ouvintes para que confessassem seus furtos, restituíssem o que lhes era possível e mudassem de vida e de ofício. 
Figurativizada pelo peixe quatro-olhos, o tema da vaidade é enaltecido pelo missionário que, ao olhar atentamente para o animal, percebe que os pares de olhos do peixe são dispostos de maneira que ele possa observar tanto o mar como o céu. Em função disso, o narrador infere que tal espécie nos ensina que só se deve olhar para cima, para o Céu, e para baixo, para o Inferno, para que não se veja a vaidade, "porque neste mundo tudo é vaidade" (VIEIRA, 2016, p. 10).

Para finalizar os louvores aos peixes, o narrador atesta sua competência, seu saberfazer, afirmando que os peixes são criaturas do elemento que é próprio da fecundidade, a água. Aconselha-os, enfim, que tomem o exemplo das sardinhas, que são o sustento dos pobres, enquanto os olhos e os salmões alimentam os reis e os poderosos.

Partindo para a quarta parte do sermão, o pregador emprega, em seu discurso, a provocação, ao depreciar as características de algumas espécies de peixes. As repressões do narrador, em geral, são dirigidas aos comportamentos dos peixes que se comem uns aos outros; por exemplo, os peixes grandes comem os pequenos, mostrando cobiça e cupidez, criando, assim, grandes desequilíbrios e injustiças. Por meio dessas figuras, o pregador ataca, de forma explícita, os colonos portugueses e exerce sua autoridade para persuadir o povo para um novo comportamento, com o argumento de que a terra oferece o suficiente para que todos possam se sustentar, conforme asseveram Mürge e Conte (2017).

Valendo-se do mesmo procedimento de quando tratou das virtudes dos peixes, na quinta parte do sermão, o narrador traz à tona figuras de peixes que revestem vários temas relacionados às atitudes desses animais e dos homens. Destacamos alguns temas figurativizados pelo pregador:

Quadro 1. Temas figurativizados pelo narrador

\begin{tabular}{|l|l|}
\hline \multicolumn{1}{|c|}{ Temas } & \multicolumn{1}{c|}{ Figuras } \\
\hline Ira, arrogância & $\begin{array}{l}\text { Peixes roncadores: mesmo sendo peixes pequenos, roncam bastante, } \\
\text { simbolizando, assim, os homens arrogantes que se julgam superiores aos } \\
\text { demais: "É possível que sendo vós uns peixinhos tão pequenos haveis de } \\
\text { ser as roncas do mar?" (VIEIRA, 2016, p. 16) }\end{array}$ \\
\hline Oportunismo & $\begin{array}{l}\text { Peixe pegador: como o próprio nome diz, são animais que se grudam aos } \\
\text { maiores, não os largando mais: "Pegadores se chamam estes de que agora } \\
\text { falo, e com grande propriedade, porque sendo pequenos, não só se chegam } \\
\text { a outros maiores, mas de tal sorte se lhes pegam aos costados que jamais } \\
\text { os desferram" (VIEIRA, p. 14) }\end{array}$ \\
\hline
\end{tabular}




\begin{tabular}{|l|l|}
\hline Ambição, vaidade & $\begin{array}{l}\text { Peixe voador: é um peixe que, tendo barbatanas maiores, não contente } \\
\text { com essa condição, quer ser ave. No entanto, deixam de serem peixes e } \\
\text { não conseguem ser ave, ou seja, não são coisa alguma, conforme Mürge } \\
\text { e Conte (2017). Vieira (2016, p. 19) adverte: "quem quer mais do que Ihe } \\
\text { convém, perde o que quer, e o que tem". }\end{array}$ \\
\hline $\begin{array}{l}\text { Traição e } \\
\text { hipocrisia }\end{array}$ & $\begin{array}{l}\text { Polvo: possui uma aparência de criatura mansa e um ar inofensivo, mas na } \\
\text { essência, é maldoso, hipócrita e traiçoeiro. Por esse motivo, representa os } \\
\text { sujeitos traidores e hipócritas: "E debaixo desta aparência tão modesta, ou } \\
\text { desta hipocrisia tão santa [...] o dito polvo é o maior traidor do mar" (VIEIRA, } \\
\text { 2016, p. 21). }\end{array}$ \\
\hline
\end{tabular}

Fonte: Elaboração própria

Por fim, na parte final do sermão, antes de propor aos peixes que louvem a Deus pelo que são, o narrador evidencia a água como um elemento puro, claro e cristalino, espelho não só da terra, mas também do céu. Por meio dela, nada se pode ocultar e nem dissimular. Assim, nota-se que mesmo nos mares que habitam os peixes há também falsidades, enganos, fingimentos, embustes, ciladas e traições. Porém, mesmo diante disso, esses seres da água, segundo o narrador, possuem duas boas qualidades: ouvem e não falam.

Diante disso, o narrador explica-lhes o motivo de terem ficado fora dos sacrifícios. Segundo ele, esses animais eram os únicos que podiam chegar vivos ao sacrifício, e Deus não quer que se ofereçam aos mortos. Por meio da provocação, o enunciador do texto pretende, nesse ponto, alcançar aos homens, visto que muitos deles chegam mortos ao altar de Deus em decorrência de seus pecados.

Observa-se que, na geração de sentido do texto, o narrador, para dar maior concretude às estruturas abstratas do nível narrativo, transforma-as em temas abstratos e reveste esses temas com figuras do mundo natural.

Enfim, com a análise desses percursos figurativos e temáticos, desvendam-se as linhas isotópicas do sermão que revelam novas leituras, as quais asseguram a coerência semântica do discurso, uma das condições para que o texto seja coerente. Dentro de um jogo de ideias e com eloquência persuasiva, o narrador instalado no texto traz, na narrativa, o interior de cada um, mostrando os malefícios dos humanos que buscam apenas o poder e os bens materiais.

\section{Conclusão}

A partir das considerações expostas na análise, pretendemos evidenciar que o narrador do Sermão de Santo Antônio aos Peixes, para estabelecer um contrato de confiança e persuadir 
seus destinatários a aceitar o que ele propõe, recorre a vários tipos de manipulação; no entanto, cabe aos seus ouvintes reconhecer os valores empregados na manipulação, uma vez que o fazer-persuasivo ou fazer-crer do destinador tem como contrapartida o fazer-interpretativo ou o crer do destinatário, de que decorre a aceitação ou a recusa do contrato. Nota-se também que, nesse jogo persuasivo, o narrador mostra-se como um grande reconhecedor dos valores das palavras de Cristo, o que parece conferir alto grau de credibilidade a seu fazer persuasivo.

Com relação aos investimentos figurativos e temáticos, infere-se que o sermão é um texto riquíssimo desses elementos e nos conduz a uma temática englobante, ou seja, apresenta claras repercussões do tema da corrupção decorrente dos vícios e repressões humanas.

Por fim, diante disso, podem-se apontar as linhas isotópicas, que se desdobram a partir da reiteração dos temas e a recorrência das figuras no sermão, que passa a ser visto como um manual de pensar e viver no mundo. Embora tenha sido escrito em 1654, leituras e temas transversais contemporâneos a qualquer sociedade são delineados e nos conduzem à compreensão de que Vieira foi a expressão de homem que queria um mundo com menos injustiças e atrocidades entre o poder e o povo. O missionário aparece como um transgressor dos limites do seu tempo, pois não se isentou de participar das ações políticas da época, em um contexto em que a Igreja, a qual estava diretamente ligado, estava também vinculada ao poder. Batalhou pelo seu direito à palavra, porém a decepção e a desilusão Ihe foram inevitáveis, por isso acabou seus dias isolado sem, contudo, deixar de fazer jus aos seus pensamentos por meio dos registros de seus sermões.

\section{REFERÊNCIAS}

BARROS, D. L. P. Estudos do Discurso. In: FIORIN, J. L. (org.) Introdução à linguística II: princípios de análise. 4. ed. São Paulo: Contexto, 2005a. p. 187-219.

BARROS, D. L. P. Teoria Semiótica do Texto. São Paulo: Ática, 2005b.

BARROS, D. L. P. Teoria do discurso: fundamentos semióticos. São Paulo: Humanitas/ FLLCH/USP, 2001.

BATISTOTE, M. L. F. Semiótica francesa: busca de sentido em narrativas místicas. Campo Grande: Ed. UFMS, 2012.

BERTRAND, D. Narratividade e discursividade: pontos de referência e problemáticas. Significação - Revista Brasileira de Semiótica, São Paulo, Editora Annablume, n. 19, p. 9-50, 2003a. 
BERTRAND, D. Caminhos da semiótica literária. Bauru: EdUSC, 2003b.

CARDOSO, M. M. O jogo de debreagens na narrativa "O espelho de tinta". Estudos Semióticos, São Paulo, v. 11, n. 2, p. 33-39, 2015.

FIORIN. J. L. As astúcias da enunciação: as categorias de pessoa, espaço e tempo. 3. ed. São Paulo: Contexto, 2016.

FIORIN. J. L. Elementos de Análise do Discurso. São Paulo: Contexto, 2005.

FIORIN. J. L. Sendas e Veredas da Semiótica Narrativa e Discursiva. Delta - Revista de Documentação de Estudos em Linguísticas Teórica e Aplicada, São Paulo, v. 15, n. 1, p. 177207, 1999.

GREIMAS, A. J.; COURTÉS, J. Dicionário de semiótica. Tradução Alceu Dias Lima et al. São Paulo: Cultrix, 1979.

MÜGGE, E.; CONTE, D. "Sermão de Santo Antônio aos Peixes" ou a metáfora do imaginário colonial português. Revista Navegações, v. 10, n. 2, p. 131-140, jul.-dez. 2017.

VIEIRA, A. Sermão e Santo Antônio aos Peixes. São Paulo: Poeteiro Editor Digital: Projeto Livro Livre, 2016. Disponível em: https://drive.google.com/file/ d/OB9CNZ3uU92IVcU02cIRiWkJ4VGs/view. Acesso em: 22 jan. 2019. 